\section{MYOCARDIAL PERFORMANCE IN ELDERLY PATIENTS AFTER CARDIOPULMONARY BYPASS IS SUPPRESSED BY TUMOR NECROSIS FACTOR}

The aim of this study was to determine whether elderly patients (aged $\geq 65$ years, $n=20$ ) in comparison with younger patients (aged $\leq 55$ years, $n=$ 23) demonstrate a different biochemical and hemodynamic response to coronary artery bypass operations. In the elderly group, we calculated a smaller body surface area $(p<0.01)$ than that in the younger group, and more female patients were included in this group $(p<0.05)$. During cardiopulmonary bypass, the elderly had higher endotoxin plasma concentrations $(p<0.01)$ than the younger patients, and significantly more circulating tumor necrosis factor-alpha was found after operation $(p<$ 0.04). In the intensive care unit, the elderly patients had a significantly higher pulmonary capillary wedge pressure $(p<0.001)$, a higher mean pulmonary artery pressure $(p<0.01)$, and a lower calculated left ventricular stroke work index $(p<0.05)$. Multivariate analysis for the postoperative outcome showed that the intergroup differences in tumor necrosis factor-alpha, mean pulmonary artery pressure, and pulmonary capillary wedge pressure could be explained mainly by the difference in age between the groups and that the calculated left ventricular stroke work index difference could be explained by the difference in circulating tumor necrosis factor-alpha levels. Thus in elderly patients higher circulating endotoxin and tumor necrosis factor-alpha concentrations were detected than in younger patients, which clinically resulted in a suppressed myocardial performance. (J THORAC CARDIOVASC SURG 1995;110:1663-9)

Henk te Velthuis, PhD, ${ }^{a}$ Piet G. M. Jansen, MD, PhD, ${ }^{a}$

Heleen M. Oudemans-van Straaten, MD, ${ }^{a}$ Augueste Sturk, PhD, ${ }^{b}$

León Ejjsman, $\mathrm{MD}, \mathrm{PhD},{ }^{a}$ and Charles R. H. Wildeviur, $\mathrm{MD}, \mathrm{PhD},{ }^{\mathrm{a}}$

Amsterdam and Leiden, The Netherlands
Tumenting umor necrosis factor-alpha $(\mathrm{TNF} \alpha)$ is a strong mediator of inflammation in human beings and animals. Administration of TNF $\alpha$ to human beings and animals elicits manifestations of sepsis and septic shock, including fever, acidosis, leukopenia, histopathologic evidence of organ failure, and death. ${ }^{1,2}$ TNF $\alpha$-induced hemodynamic changes include elevated cardiac output, tachycardia, and decreased systemic vascular resistance. ${ }^{2}$ Recently, TNF $\alpha$ induced negative inotropic effects on the heart were

From the Centre for Cardiopulmonary Surgery Amsterdam, Amsterdam, ${ }^{a}$ and the Department of Clinical Chemistry, University Hospital Leiden, Leiden, ${ }^{\mathrm{b}}$ The Netherlands.

Received for publication Sept. 2, 1994.

Accepted for publication March 8, 1995.

Address for reprints: Ch. R. H. Wildevuur, MD, PhD, Department of Cardiopulmonary Surgery, Onze Lieve Vrouwe Gasthuis, P. O. Box 95500, 1090 HM Amsterdam, The Netherlands.

Copyright (C) 1995 by Mosby-Year Book, Inc.

$0022-5223 / 95 \$ 5,00+0 \quad \mathbf{1 2} / \mathbf{1} / \mathbf{6 4 5 9 1}$ described that lead to an impaired myocardial performance. ${ }^{3}$ Several studies reported TNF $\alpha$ in the circulation of patients after cardiac operations, ${ }^{4,5}$ suggesting that this may play a pivotal role in postoperative complications after cardiac operations.

After cardiac operations with cardiopulmonary bypass (CPB) a sepsislike syndrome may develop, induced by a systemic inflammatory response. ${ }^{6}$ The clinical manifestations of this sepsislike syndrome resemble the endotoxin- and TNF $\alpha$-induced response in human beings and animals. ${ }^{1,7} \mathrm{TNF} \alpha$ synthesis may be induced by complement activation or endotoxemia, which have both been reported to occur during CPB., 6, 8-10 Experimental endotoxemia in human beings induced an inflammatory response with early $\mathrm{TNF} \alpha$ production. ${ }^{7}$ Recently, we reported that endotoxemia during $C P B$ is induced by perfusion-related factors and not by contamination of the supplied fluids. ${ }^{10}$ Endotoxemia was most severe in patients (1) with the largest drop in oncotic 
Table I. Patient characteristics, surgical data, fluid balance, and vasoactive medications

\begin{tabular}{lccc}
\hline & Age $\leq 55 y r$ & Age $\geq 65 y r$ & $\begin{array}{c}p \\
\text { Value }\end{array}$ \\
\hline Age (yr) & $50 \pm 1.5$ & $69 \pm 1.3$ & $<0.001$ \\
No. of patients & 23 & 20 & \\
Gender (female/ & $1 / 22$ & $5 / 15$ & $<0.05^{*}$ \\
$\quad$ male) & & & \\
B Surface A (m ${ }^{2}$ ) & $2.06 \pm 0.04$ & $1.94 \pm 0.05$ & $<0.005$ \\
Height (cm) & $178 \pm 3.0$ & $174 \pm 3.2$ & $<0.05$ \\
Body weight (kg) & $86 \pm 3.8$ & $79 \pm 3.9$ & $<0.05$ \\
LVEDP (mm Hg) & $12 \pm 2.7$ & $13 \pm 1.9$ & NS \\
CPB time (mins) & $99 \pm 11$ & $108 \pm 17$ & NS \\
Crossclamp time & $66 \pm 9$ & $68 \pm 12$ & NS \\
$\quad$ (mins) & & & \\
No. of distal anas- & $3.2 \pm 0.5$ & $3.6 \pm 0.8$ & NS \\
$\quad$ tomoses & & & \\
Fluid balance $\dagger(\mathrm{L})$ & $4.2 \pm 1.1$ & $4.1 \pm 1.0$ & NS \\
Diuresis $\dagger(\mathrm{L})$ & $7.0 \pm 1.2$ & $6.2 \pm 1.0$ & NS \\
Blood loss $\dagger(\mathrm{L})$ & $1.8 \pm 0.4$ & $1.7 \pm 0.6$ & NS \\
Dopamine $\dagger(\mu \mathrm{g})$ & $378 \pm 99$ & $352 \pm 99$ & NS \\
Nitroglycerin $\dagger(\mathrm{mg})$ & $20 \pm 9.4$ & $25 \pm 7.8$ & NS \\
\hline
\end{tabular}

Data are presented as mean $\pm 95 \%$ confidence interval of the mean. LVEDP, LV end-diastolic pressure; $N S$, not significant.

*Determined by Fisher's exact test.

†From induction of anesthesia until 18 hours after arrival in the ICU.

pressure during $\mathrm{CPB},(2)$ who had a vasoconstriction reaction on onset of $\mathrm{CPB}$, and (3) with long duration of CPB. Elderly patients might have a more sensitive reaction to these factors and therefore might be more at risk for development of endotoxemia. This would be in agreement with statistical evaluations that show that the age of the patient is one of the major risk factors in predicting mortality and morbidity in cardiac operations. ${ }^{11,12}$ After cardiac operations, the principal causes of death in elderly patients were cardiac related. ${ }^{12}$

The aim of this study was to determine whether the biochemical and hemodynamic responses to CPB in elderly patients are different from those in younger patients. Therefore we measured TNF $\alpha$ levels and hemodynamic parameters and estimated the myocardial performance of patients 55 years old or younger and 65 years old or older during CPB and during the intensive care unit (ICU) stay. In a subpopulation, we verified whether these parameters were associated with circulating endotoxin concentrations.

\section{Material and methods}

Patients and study design. Forty-three patients who underwent nonurgent coronary artery bypass grafting were selected from a databank that served several clinical studies during the past 2 years. The inclusion criteria for these studies were age between 45 and 75 years, left ventricular (LV) end-diastolic pressure less than $20 \mathrm{~mm}$ $\mathrm{Hg}$, ejection fraction greater than $40 \%$, and aspirin therapy stopped more than 3 days before operation. The total group $(n=85)$ was divided into two age groups according to the 25th and the 75th percentiles: patients younger than or equal to age 55 years $(n=23)$ and patients older than or equal to age 65 years $(n=20)$. None of the patients had major organ dysfunctions before coronary artery bypass grafting or perioperative myocardial infarctions. All studies were done at the Free University Hospital, Amsterdam, The Netherlands and were approved by the local medical ethical committee. All patients gave informed consent for the specific study.

Technique of anesthesia and CPB. On the day of the operation, patients received their usual early morning dose of antianginal medication and $5 \mathrm{mg}$ lorazepam. Anesthesia was induced with intravenous fentanyl 30 $\mu \mathrm{g} / \mathrm{kg}$, pancuronium bromide $0.1 \mathrm{mg} / \mathrm{kg}$, and diazepam 0.1 $\mathrm{mg} / \mathrm{kg}$ and maintained by supplemental doses of these drugs. After endotracheal intubation was accomplished, patients received assisted ventilation to normocapnia with an oxygen-air mixture. The standard perfusion protocol aimed at a hematocrit value of $22 \%$ to $23 \%$ during CPB. CPB was done with moderate systemic hypothermia $\left(28^{\circ}\right.$ to $30^{\circ} \mathrm{C}$ ), nonpulsatile flow (2.2 to $2.4 \mathrm{~L} / \mathrm{min}$ per square meter) and cold high-potassium crystalloid cardioplegia $\left(4^{\circ} \mathrm{C}\right)$. The $\mathrm{CPB}$ circuit consisted of a closed venous reservoir, a roller pump, and a membrane oxygenator (Ultrox-1, Avecor, Plymouth, Minn., or Univox, Baxter Healthcare Corp., Irvine, Calif.) with an arterial line filter and polyvinyl chloride tubing. A standard cannulation technique was used with a cannula in the ascending aorta and the right atrium (two-stage venous cannula). Patients were weaned from $\mathrm{CPB}$ with dopamine $0.5 \mu \mathrm{g}$. $\mathrm{kg}^{-1} \cdot \min ^{-1}$ and nitroglycerin $0.5 \mu \mathrm{g} \cdot \mathrm{kg}^{-1} \cdot \mathrm{min}^{-1}$ or bigher doses if necessary. After termination of CPB, heparin was neutralized with an equal dose of protamine sulfate.

Sample scheme and biochemical assays. Blood samples were taken from the radial artery or the arterial line of the extracorporeal circuit before induction of anesthesia (S0), 10 minutes after the start of CPB (S1), 10 minutes after removal of the aortic crossclamp (S2), at cessation of CPB (S3), 1 hour after the patient arrived in the ICU (S4), 4 hours after arrival in the ICU (S5), and 18 hours after arrival in the ICU (S6). Blood samples for TNF $\alpha$ determination were taken at points $\mathrm{S} 0, \mathrm{S3}, \mathrm{S} 4, \mathrm{~S} 5$, and $\mathrm{S} 6$, and endotoxin samples were taken at points $\mathrm{S} 0, \mathrm{~S} 1, \mathrm{~S} 2, \mathrm{~S} 3, \mathrm{~S} 4$, and S6. Blood samples for TNF $\alpha$ determination were collected in $5 \mathrm{ml}$ citrate-anticoagulated tubes. The samples were immersed in ice immediately after collection and processed within 1 hour. Platelet-poor plasma was prepared by centrifugation at $4^{\circ} \mathrm{C}$ for 10 minutes at 3000 $\mathrm{rpm}$. The samples were stored at $-70^{\circ} \mathrm{C}$.

$T N F \alpha$. TNF $\alpha$ concentrations were determined with an immunoradiometric assay (Medgenix, Brussels, Belgium). The TNF $\alpha$ immunoradiometric assay has a detection limit of $5 \mathrm{ng} / \mathrm{L}$ and intraassay and interassay coefficients of variance of $6 \%$ and $7 \%$, respectively, at $66 \mathrm{ng} / \mathrm{L}$. The TNF $\alpha$ data presented were not corrected for hemodilution. 
Endotoxin. Endotoxin concentrations were available in a subpopulation of 11 patients: 6 patients in the younger group and 5 patients in the elderly group. Endotoxin levels were estimated with the chromogenic Limulus assay (Coatest Endotoxin, Kabi-Chromogenix, Mölndal, Sweden, which included Limulus amebocyte lysate preparations produced by Whittaker Bioproducts, Inc., Walkersville, Md.) as described before. ${ }^{13}$ Blood for the Limulus assay was collected under pyrogen-free conditions in monovettes (Sarstedt, Nümbrecht, Germany), containing pyrogen-free heparin (Thromboliquine, Organon, Oss, The Netherlands) at a final concentration of $30 \mathrm{IU} \cdot \mathrm{ml}^{-1}$, and the tubes were immediately immersed in crushed ice. Platelet-rich plasma was prepared by centrifugation for 10 minutes at $190 \mathrm{~g}$ and $4^{\circ} \mathrm{C}$ and was stored in duplicate portions in polystyrene tubes (Falcon 2063, Oxnard, Calif.) at $-70^{\circ} \mathrm{C}$. Endotoxin concentrations are given in endotoxin units per milliliter platelet-rich plasma $\left(\mathrm{EU} \cdot \mathrm{ml}^{-1}\right)$. The detection limit was $0.036 \mathrm{EU} \cdot \mathrm{ml}^{-1}$. The clinical decision limit for an endotoxin-positive sample was $0.060 \mathrm{EU} \cdot \mathrm{ml}^{-1}$. Endotoxemia was defined as the area under the curve of endotoxin from samples S0 through S3 (before and during $\mathrm{CPB}$ ). The endotoxin data presented were not corrected for hemodilution. With the endotoxin standard presently used $0.012 \mathrm{EU}$ corresponds to $1 \mathrm{pg}$.

Hemodynamic parameters and volume management. Hemodynamic parameters were assessed with the aid of a radial artery catheter and a Swan-Ganz catheter (Baxter Healthcare Corp., Edwards Division, Santa Ana, Calif.). The heart rate, mean arterial pressure, central venous pressure, pulmonary artery pressure, pulmonary capillary wedge pressure, and cardiac output (thermodilution method) were measured after induction of anesthesia (S0) and at 1 hour (S4), 4 hours (S5), and 18 hours (S6) after the patient arrived in the ICU. The following parameters were calculated: cardiac index $=$ cardiac output/body surface area (BSA); stroke volume index = (cardiac index/heart rate) $\times 1000 ; \mathrm{LV}$ stroke work index $=$ (mean arterial pressure - pulmonary capillary wedge pressure) $\times$ stroke volume index $\times 0.0136$; and right ventricular stroke work index $=$ (pulmonary artery pressure - central venous pressure $) \times$ stroke volume index $\times 0.0136$. The fluid balance was defined as fluid administration - (diuresis + blood loss) and was calculated from induction of anesthesia until 18 hours after operation. The distribution of insensible fluid losses was considered even among both groups and not included in the calculation.

Statistics. Statistical analysis was done with the use of Statview SE + Graphics computer software (Abacus Concepts, Inc., Berkeley, Calif.). An unpaired two-tailed Student's $t$ test was done to determine differences between groups, except for the endotoxin data. Differences in endotoxin concentrations were determined with the Mann-Whitney $U$ test. Differences between the ratio of female to male patients between the groups were determined with Fisher's exact test. To analyze changes within each group, one-factor analysis of variance for repeated measures was done, supplemented with the Scheffé post hoc test. Additionally, two-factor analysis of variance for repeated measures was used to assess intergroup comparisons and group-time interactions during ICU stay. A nonsignificant group-time interaction indicates that the

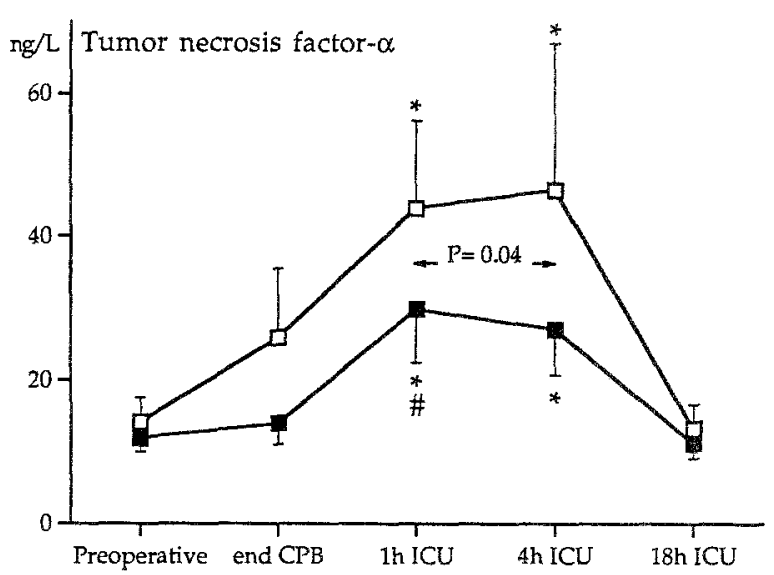

Fig. 1. Circulating TNF $\alpha$ concentrations in 20 elderly patients (aged $\geq 65$ years) (open squares) and 23 younger patients (aged $\leq 55$ years) (solid squares) during and after cardiac operation. During ICU stay (arrows), two-factor analysis of variance for repeated measures yielded intergroup differences in circulating $\mathrm{TNF} \alpha$ concentrations. Data are presented as means $\pm 95 \%$ confidence interval of mean. ${ }^{*} p<0.05$ compared with preoperative sample; ${ }^{\#} p<0.05$ compared with previous sample.

difference in hemodynamics in the ICU is explained by difference in age of the patient groups and this difference would not change as a result of time. To analyze the influence of other parameters (besides age), multivariate analysis was done for the significantly different hemodynamic parameters and circulating TNF $\alpha$ levels during the ICU stay. Regression analysis was done to determine the correlation between the area under the curve of endotoxin during CPB and the mean peak of TNF $\alpha$ levels during the ICU stay. In all cases a two-sided $p$ value less than 0.05 was considered to be significant. Data are presented as means $\pm 95 \%$ confidence intervals of the mean, unless stated otherwise.

\section{Results}

The difference in age between the younger and elderly patients groups was 19 years (Table I). The elderly patients were smaller and lighter and had therefore a smaller BSA than the younger patients. Significantly more women were enrolled in the elderly group. There were no differences between the patient groups concerning LV end-diastolic pressure, number of distal anastomoses, or duration of crossclamping and CPB. Also, no differences were found in fluid balance, diuresis, blood loss, or use of vasoactive medication.

Peak levels of TNF $\alpha$ were reached within the first hours after patient arrival in the ICU (Fig. 1). 


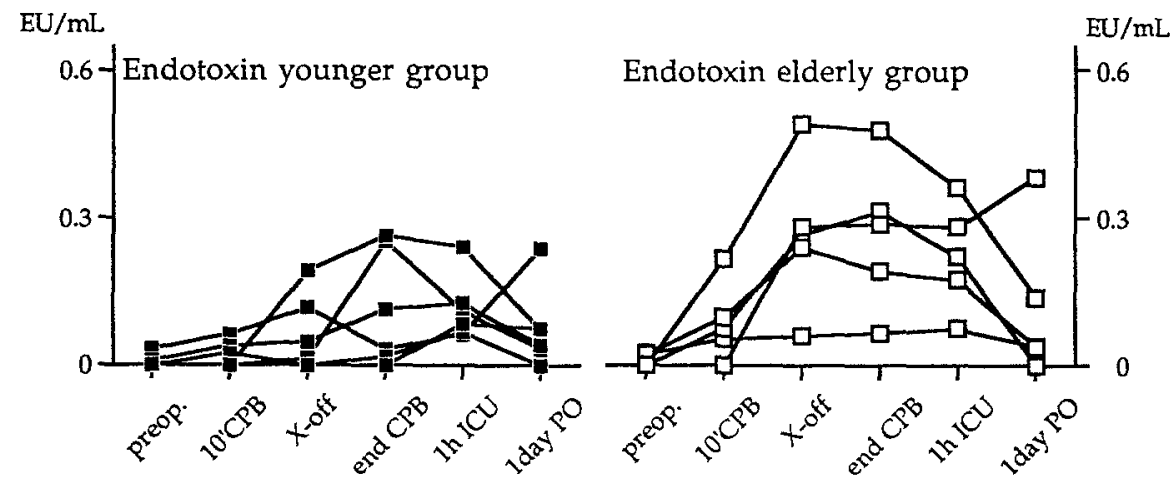

Fig. 2. Circulating endotoxin concentrations in six younger patients (aged $\leq 55$ years) and five elderly patients (aged $\geq 65$ years) during and after cardiac operation. Significant difference was observed after crossclamp removal $(X$-off, $p<0.05)$ between elderly and younger patients (Mann-Whitney test). 1 Day PO, 18 hours after arrival at ICU.

Intragroup differences were observed in both groups. Circulating TNF $\alpha$ levels rose significantly 1 hour after patient arrival in the ICU and remained elevated at 4 hours in the ICU. At measurement on the first postoperative day TNF $\alpha$ concentrations had returned to baseline values. An intergroup difference was observed during the first hours of the ICU stay ( $p=0.04$, no interaction with time). Younger patients had mean peak levels of TNF $\alpha$ (mean of 2 measurements at 1 and 4 hours in the ICU) of $28 \pm$ $6 \mathrm{ng} \cdot \mathrm{L}^{-1}$ and elderly patients had corresponding levels of $47 \pm 15 \mathrm{ng} \cdot \mathrm{L}^{-1}$.

In 10 of 11 patients endotoxemia developed during the cardiac operation (Fig. 2). None of the patients had detectable endotoxin concentrations in the blood before induction of anesthesia. In three of five elderly patients endotoxin concentrations higher than $0.060 \mathrm{EU} \cdot \mathrm{ml}^{-1}$ were observed immediately after the onset of CPB (Fig. 2, right), whereas this endotoxin concentration was observed at that point in one of six younger patients not significant, $p=$ 0.06 , Fisher's exact test) (Fig. 2, left). After removal of the aortic crossclamp a significant difference was observed between the groups ( $p<0.05$ ). The extent of endotoxemia was more pronounced in the elderly patients (elderly patients $0.443 \mathrm{EU} \cdot \mathrm{h} \cdot \mathrm{ml}^{-1}$, range 0.127 to 0.797 ; younger patients $0.066 \mathrm{EU}$. $\mathrm{hr} \cdot \mathrm{ml}^{-1}$; range 0 to $0.162 ; p=0.02$ ). There was no significant correlation between the area under the curve of endotoxin and mean peak of TNF $\alpha$ levels in the corresponding patients $\left(r^{2}=0.34, p=0.06\right)$.

Changes in the measured and calculated hemodynamic parameters of the young and elderly patient groups are depicted in Fig $3, A$ and $B$, respectively. The course of values for mean arterial pressure is not presented because the mean arterial pressure is one of the targets of treatment in the ICU and, therefore, no intragroup changes were observed in either group. Intragroup differences were found in all presented parameters except mean pulmonary artery pressure. Heart rate and cardiac index increased in both younger and elderly patients in the ICU. The central venous pressure and the pulmonary capillary wedge pressure significantly dropped after patient arrival at the ICU in the younger patients, whereas in the elderly both pressures remained unchanged. In the younger patients, the stroke volume index and both the left and right ventricular stroke work indices increased in the ICU, whereas in the elderly only an increase in LV stroke work index was observed 18 hours after arrival at the ICU and all other parameters remained unchanged. We determined intergroup differences in the measured hemodynamic parameters in the ICU. In the elderly patients, a higher pulmonary capillary wedge pressure $(p=0.001$, no interaction with time) and a higher mean pulmonary artery pressure ( $p=0.006$, no interaction with time) were observed compared with these valves in the younger patient group (Fig. 3, $A$ ). Among all calculated hemodynamic parameters, we found that the LV stroke work index was significantly lower in the elderly patients than in the younger patients ( $p=$ 0.04 , no interaction with time). No significant intergroup differences were observed in central venous pressure, pulmonary artery pressure, heart rate, cardiac index, stroke volume index $(p=0.06$, no interaction with time), or right ventricular stroke work index.

To analyze whether the intergroup differences 

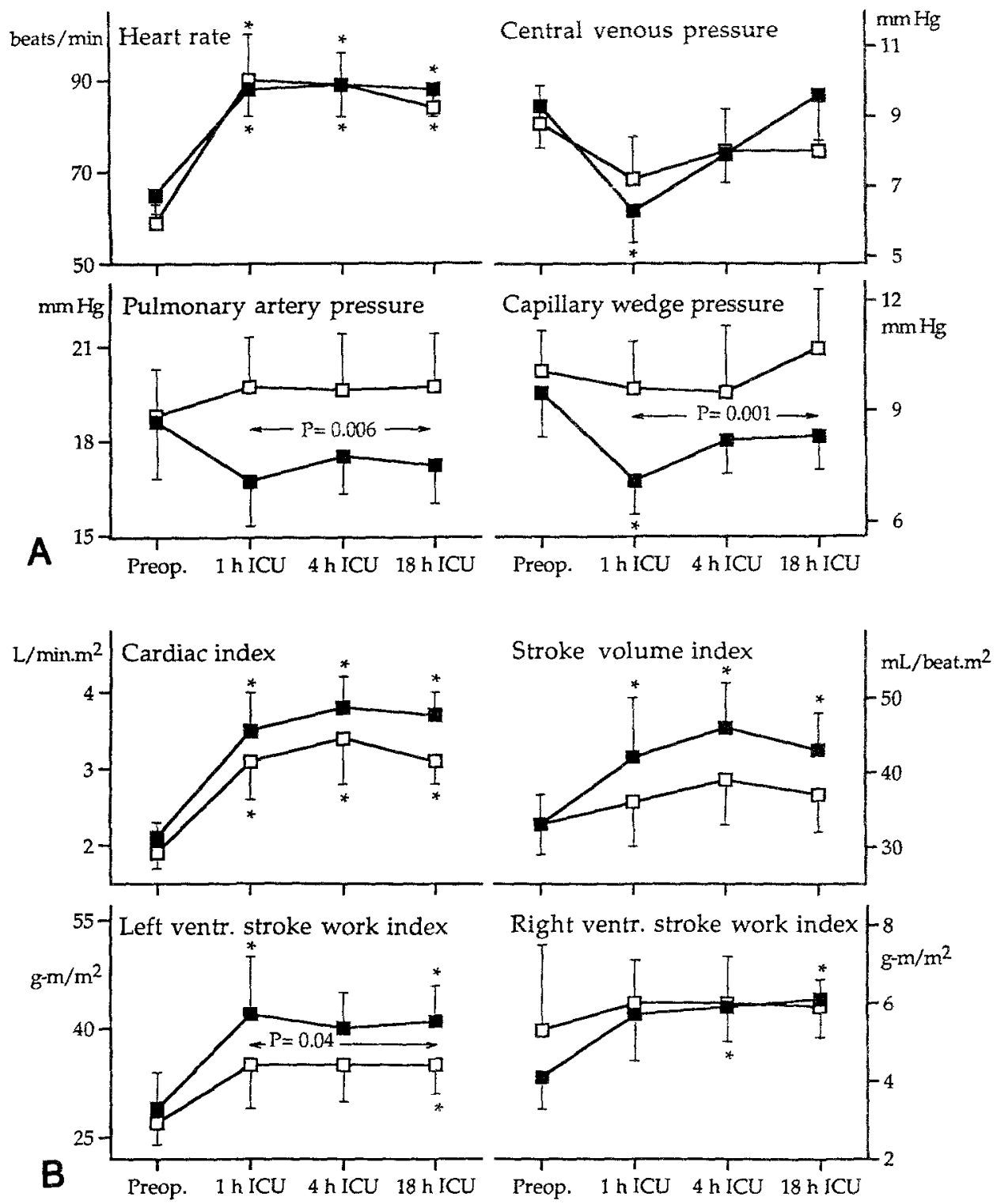

Fig. 3. Hemodynamic profile of elderly (open squares) and younger (solid squares) patients during ICU stay. A, Measured hemodynamic parameters; B, calculated parameters. During ICU stay (arrows), two-factor analysis of variance for repeated measures yielded intergroup differences in pulmonary capillary wedge pressure, mean pulmonary artery pressure, and LV stroke work index. * $p<0.05$ compared with preoperative sample.

observed in the ICU could indeed be explained by the difference in age between the groups, multivariate analysis of variance was done with age and other significantly different factors including BSA, gender, and TNF $\alpha$ level (Table II). The BSA and TNF $\alpha$ were divided into two categories according to the median value of the population: low TNF $\alpha$, less than $28.2 \mathrm{ng} \cdot \mathrm{L}^{-1}(n=21)$, and high TNF $\alpha, 28.2 \mathrm{ng} \cdot \mathrm{L}^{-1}$ or greater $(n=22)$, and low BSA, less than $1.99 \mathrm{~m}^{2}$ $(n=20)$, and high BSA, $1.99 \mathrm{~m}^{2}$ or greater $(n=23)$.
The multivariate analysis showed that the intergroup difference in TNF $\alpha$ level and mean pulmonary artery pressure could only be explained by the difference in age between the groups and not by the difference in gender or BSA. The intergroup difference in pulmonary capillary wedge pressure, however, was explained by the difference in both age and BSA, independently $(p=0.50$ for the interrelation between age and BSA for pulmonary capillary wedge pressure). The intergroup difference in LV 
Table II. Multivariate analysis for TNF $\alpha$ level and hemodynamic parameters in the ICU

\begin{tabular}{lccl}
\hline & \multicolumn{3}{c}{$p$ Values } \\
\cline { 2 - 4 } Parameter & TNF $\alpha$ /age & gender/age & BSA/age \\
\hline TNF $\alpha$ level & - & $0.28 / 0.03$ & $0.82 / 0.03$ \\
Mean PAP & $0.34 / 0.003$ & $0.84 / 0.003$ & $0.09 / 0.01$ \\
PCWP & $0.66 / 0.03$ & $0.76 / 0.02$ & $0.04 / 0.005^{*}$ \\
LV SWI & $0.001 / 0.41$ & $0.09 / 0.31$ & $0.36 / 0.29$ \\
\hline
\end{tabular}

$P$ values of two-factor analysis of variance. TNF $\alpha$ catagories: low TNF $\alpha$, less than $28.2 \mathrm{ng} \cdot \mathrm{L}^{-1}$, and high $\mathrm{TNF} \alpha, 28.2 \mathrm{ng} \cdot \mathrm{L}^{-1}$ or greater; BSA catagories: small BSA, less than $1.99 \mathrm{~m}^{2}$, and large BSA, $1.99 \mathrm{~m}^{2}$ or greater. $P A P$, Pulmonary artery pressure; $P C W P$, pulmonary capillary wedge pressure; $S W I$, stroke work index.

*No interaction between BSA and age, $p=0.50$.

stroke work index was explained by the difference in $\mathrm{TNF} \alpha$ level and not by age, gender, or BSA. The area under the curve of endotoxin was not included in the two-factor analysis of variance because of the low number of patients with available endotoxin data.

\section{Discussion}

Elderly and younger patients demonstrated a different biochemical and hemodynamic response to $\mathrm{CPB}$. A more pronounced endotoxemia developed in elderly patients during $\mathrm{CPB}$ and higher circulating TNF $\alpha$ concentrations were detected in the ICU. The significantly higher TNF $\alpha$ plasma concentrations in the elderly patients were probably induced by the more pronounced endotoxemia during CPB. The higher circulating $\mathrm{TNF} \alpha$ concentrations were associated with a lower calculated LV stroke work index, indicating that the high TNF $\alpha$ plasma concentrations might be the causative factor of the impaired LV performance.

A clear difference in hemodynamics was measured between elderly and younger patients in the ICU, although no differences were observed in fluid balance, blood loss, diuresis, or use of vasoactive medication. In elderly patients significantly higher pulmonary capillary wedge pressures and mean pulmonary artery pressures were determined compared with respective valves in younger patients. No intragroup changes were determined in the mean pulmonary artery pressures and only a drop in pulmonary capillary wedge pressures was observed in the younger patients after arrival at the ICU. However, the levels of both hemodynamic parameters were clearly different between younger and elderly patients.

The statistical analysis of the calculated hemody- namic parameters in the ICU showed clear intragroup differences in stroke volume index and LV stroke work index. Significant increases in stroke volume index and LV stroke work index were observed in the younger patients, whereas in the elderly patients no or small changes from baseline valves were determined. Heart rate and cardiac index increased equally in the ICU, but a small, nonsignificant, intergroup difference in cardiac index was observed in the ICU, which caused a clear trend in the intergroup difference in the stroke volume index $(p=0.06)$. In the younger patients, the combination of a higher stroke volume index and a lower pulmonary capillary wedge pressure resulted in the higher calculated LV stroke work index in the ICU than that in the elderly. Additionally, the RV stroke work indices in both groups were equal in the ICU. These observations, combined with the equal increases in heart rate, cardiac index, and fluid balance, indicate that in elderly patients the myocardial performance is suppressed.

Significant differences were determined in the demographic parameters of weight, height, BSA, and gender of the patients groups. To analyze the influence of these parameters, besides age, on the postoperative outcome multivariate analysis of variance was done. Before we entered TNF $\alpha$ level into the analysis, we showed that the age of patients and not gender or BSA explained the difference in TNF $\alpha$ in the ICU. The multivariate analysis showed that the difference in age of the patients also explained the mean pulmonary artery pressures in the ICU, whereas both BSA and age explained the difference in pulmonary capillary wedge pressures in the ICU. The differences in circulating TNF $\alpha$ levels within the first hours in the ICU did not explain the outcome in these measured parameters. However, for the LV stroke work index the circulating TNF $\alpha$ levels explained the intergroup difference, whereas no significant influences of either age, gender, or BSA could be determined. Thus the difference in age between the groups resulted in higher circulating TNF $\alpha$ levels in elderly patients in the ICU, which subsequently resulted in a lower LV stroke work index. The TNF $\alpha$-induced clinical effects resulted in a diminished LV contractility in the ICU.

TNF $\alpha$ itself is a strong mediator of pathologic changes such as hypotension, tachycardia, and impaired organ perfusion. Also, TNF $\alpha$ induces changes in myocardial performance. Although TNF $\alpha$ induces an increase in heart rate and cardiac index, several studies have documented depression of myocardial 
performance after TNF $\alpha$ challenge. ${ }^{2,14}$ Reversible LV dysfunction was observed after 6 hours and persisted for 24 to 48 hours after injection with recombinant TNF $\alpha$ in conscious dogs. The direct negative inotropic effect of TNF $\alpha$ on isolated hamster papillary muscles is dependent on a secondary messenger. Nitric oxide (also known as endothelium-derived relaxing factor) was described as the secondary mediator that inhibited the contractility of the mammalian heart in vitro. ${ }^{2}$ Our results support the in vitro data; the suppressed calculated LV stroke work index implies an inhibited contractility of the heart.

TNF $\alpha$ synthesis can be induced by several triggers. Endotoxin was reported to be a strong inducer of cytokine production. ${ }^{7}$ Indeed, in a subpopulation of 11 patients, a significantly more pronounced endotoxemia was observed in the elderly patients. The trend in the correlation between endotoxemia and the area under the curve of TNF $\alpha$ level, with an $r^{2}$ valve of 0.34 and a probability of 0.06 , seemed to support the hypothesis of endotoxin-induced $\mathrm{TNF} \alpha$ production after CPB. These facts suggest that the difference in circulating TNF $\alpha$ levels was likely induced by endotoxin. In a previous study, we described three perfusion-related factors that caused severe endotoxemia after CPB ${ }^{10}$ Apparently, elderly patients have hemodynamically inadequate responses to low oncotic prime solutions, severe hemodilution, and hypothermia during CPB and have a greater risk of endotoxemia than younger patients.

In conclusion, in this study we showed that elderly patients had higher plasma concentrations of TNF $\alpha$ than younger patients after cardiac operation. The higher TNF $\alpha$ concentrations were most likely induced by high plasma endotoxin concentrations. The clinical effect of high TNF $\alpha$ levels was observed in a suppression of the LV performance in elderly patients in the ICU. This indicates that with the current $\mathrm{CPB}$ technique elderly patients are at higher risk for the development of postoperative cardiacrelated complications than younger patients. This is of great importance, because with increasing life expectancy and an increasing number of elderly patients undergoing coronary artery bypass grafting, morbidity and mortality will increase. Improvements in perfusion techniques will therefore be required to reduce these inflammatory reactions associated with CPB.

We thank I. Y. Koen and K. Joop for technical assistance in performing the endotoxin assays.

\section{REFERENCES}

1. Van der Poll T, Büller HR, ten Cate H, et al. Activation of coagulation after administration of tumor necrosis factor to normal subjects. N Engl J Med 1990;322: 1622-7.

2. Schirmer WJ, Schirmer JM, Fry DE. Recombinant human tumor necrosis factor produces hemodynamic changes characteristic of sepsis and endotoxemia. Arch Surg 1989;124:445-8.

3. Kinkel MS, Oddis CV, Jacob TD, Watkins SC, Hattler BG, Simmons RL. Negative inotropic effects of cytokines on the heart mediated by nitric oxide. Science 1992;257:387-9.

4. Jansen NJG, van Oeveren W, Gu YJ, van Vliet MH, Eijsman L, Wildevuur ChRH. Endotoxin release and tumor necrosis factor formation during cardiopulmonary bypass. Ann Thorac Surg 1992;54:744-8.

5. Gu YJ, van Oeveren W, Akkerman C, Boonstra PW, Huyzen RJ, Wildevuur ChRH. Heparin-coated circuits reduce the infiammatory response to cardiopulmonary bypass. Ann Thorac Surg 1993;55:917-22.

6. Kirklin JK, Westaby S, Blackstone EH, Kirklin JW, Chenoweth DE, Pacifico AD. Complement and the damaging effects of cardiopulmonary bypass. I THORAC CARdiovasc Surg 1983;86:845-57.

7. Van Deventer SJH, Büller HR, ten Cate JW, Aarden LA, Hack CE, Sturk A. Experimental endotoxemia in humans: analysis of cytokine release and coagulation, fibrinolytic, and complement pathways. Blood 1990; $76: 2520-6$.

8. Rocke DA, Gaffin SL, Wells MT, Koen Y, BrockUtine JG. Endotoxemia associated with cardiopulmonary bypass. J Thorac CARdovasc Surg 1987;93: $832-7$.

9. Mollnes TE, Videm V, Götze O, Harboe M, Opperman M. Formation of C5a during cardiopulmonary bypass: inhibition by precoating with heparin. Ann Thorac Surg 1991;52:92-7.

10. Jansen PGM, te Velthuis H, Oudemans-van Straaten $\mathrm{H}$, et al. Perfusion-related factors of endotoxin release during cardiopulmonary bypass. Eur J Cardiothorac Surg 1994;8:125 -9.

11. Parsonnet V, Dean D, Bernstein AD. A method of uniform stratification of risk for evaluating the results of surgery in acquired adult heart disease. Circulation 1989;79(Suppl):13-12.

12. Montague NT, Kouchoukos NT, Wilson AS, et al. Morbidity and mortality of coronary bypass grafting in patients 70 years of age and older. Ann Thorac Surg $1985 ; 39: 552-7$.

13. Sturk A, Janssen ME, Muylaert FR, Joop K, Thomas LLM; ten Cate JW. Endotoxin testing in blood. Prog Clin Biol Res 1987;231;371-85.

14. Pagani FD, Baker LS, Hsi C, Knox M, Fink MP, Visner MS. Left ventricular systolic and diastolic dysfunction after infusion of tumor necrosis factor- $\alpha$ in conscious dogs. J Clin Invest 1992;90:389-98. 